\title{
BMJ Open Epidemiology of uterine rupture among pregnant women in China and development of a risk prediction model: analysis of data from a multicentre, cross-sectional study
}

\author{
Wenqiang Zhan, ${ }^{1,2}$ Jing Zhu, ${ }^{3,4}$ Xiaolin Hua, ${ }^{5}$ Jiangfeng Ye, ${ }^{6}$ Qian Chen, ${ }^{1}$ \\ Jun Zhang ${ }^{7}{ }^{7}$
}

To cite: Zhan W, Zhu J, Hua X, et al. Epidemiology of uterine rupture among pregnant women in China and development of a risk prediction model: analysis of data from a multicentre, cross-sectional study. BMJ Open 2021;11:e054540. doi:10.1136/ bmjopen-2021-054540

- Prepublication history and additional supplemental material for this paper are available online. To view these files, please visit the journal online (http://dx.doi.org/10.1136/ bmjopen-2021-054540).

WZ and JZ contributed equally.

WZ and $\mathrm{JZ}$ are joint first authors.

Received 16 June 2021 Accepted 27 October 2021

Check for updates

(c) Author(s) (or their employer(s)) 2021. Re-use permitted under CC BY-NC. No commercial re-use. See rights and permissions. Published by BMJ.

For numbered affiliations see end of article.

\section{Correspondence to}

Dr Jun Zhang;

junjimzhang@sina.com and

Dr Qian Chen;

chenqian01@xinhuamed.com. cn

\section{ABSTRACT}

Objectives To describe the epidemiology of uterine rupture in China from 2015 to 2016 and to build a prediction model for uterine rupture in women with a scarred uterus.

Setting A multicentre cross-sectional survey conducted in 96 hospitals across China in 2015-2016.

Participants Our survey initially included 77789 birth records from hospitals with 1000 or more deliveries per year. We excluded 2567 births less than 24 gestational weeks or unknown and 1042 births with unknown status of uterine rupture, leaving 74180 births for the final analysis

Primary and secondary outcome measures Complete and incomplete uterine rupture and the risk factors, and a prediction model for uterine rupture in women with scarred uterus (assigned each birth a weight based on the sampling frame).

Results The weighted incidence of uterine rupture was $0.18 \%$ (95\% Cl $0.05 \%$ to $0.23 \%$ ) in our study population during 2015 and 2016. The weighted incidence of uterine rupture in women with scarred and intact uterus was $0.79 \%$ (95\% $\mathrm{Cl} 0.63 \%$ to $0.91 \%$ ) and $0.05 \%(95 \% \mathrm{Cl}$ $0.02 \%$ to $0.13 \%$ ), respectively. Younger or older maternal age, prepregnancy diabetes, overweight or obesity, complications during pregnancy (hypertensive disorders in pregnancy and gestational diabetes), low education, repeat caesarean section $(\geq 2)$, multiple abortions $(\geq 2)$, assisted reproductive technology, placenta previa, induce labour, fetal malpresentation, multiple pregnancy, anaemia, high parity and antepartum stillbirth were associated with an increased risk of uterine rupture. The prediction model including eight variables $(\mathrm{OR}>1.5)$ yielded an area under the curve (AUC) of $0.812(95 \% \mathrm{Cl} 0.793$ to 0.836$)$ in predicting uterine rupture in women with scarred uterus with sensitivity and specificity of $77.2 \%$ and $69.8 \%$, respectively.

Conclusions The incidence of uterine rupture was $0.18 \%$ in this population in 2015-2016. The predictive model based on eight easily available variables had a moderate predictive value in predicting uterine rupture in women with scarred uterus. Strategies based on predictions may be considered to further reduce the burden of uterine rupture in China.

\section{Strengths and limitations of this study}

- Our study included 96 hospitals covering most of regions in China.

- A multivariable risk prediction model for uterine rupture was established in pregnant women with a scarred uterus.

- The participating hospitals were not a random sample of all hospitals in China.

- The definitions of some pregnancy complications may have varied by hospitals.

- An independent validation in different population is needed before any clinical application.

\section{INTRODUCTION}

Uterine rupture is a serious pregnancy complication, which may occur in the intact or scarred pregnant uterus from a previous caesarean section (CS) or other uterine surgery. ${ }^{12}$ Urgent intervention is needed to prevent perinatal suffocation and death, and the mother may experience a life-threatening situation and eventually undergo perinatal hysterectomy. ${ }^{34}$ The increased awareness of the possibility of uterine rupture and dramatic consequences has led to an establishment of management guidelines when undertaking a trial of labour after caesarean (TOLAC).

The incidence of uterine rupture differed greatly in published literature, depending on the study population and the definition used. A large population-based study conducted in the USA showed that the incidence of uterine rupture was $0.24 \%$ (95\% CI $0.23 \%$ to $0.25 \%)$ in 2011 and 2012. ${ }^{5}$ A Norwegian populationbased study found that in women with a scarred uterus, the incidence of complete and incomplete uterine rupture before delivery was $0.18 \%$ and $0.37 \%$, respectively. ${ }^{6}$ In 2016, a cross-sectional study conducted in 
29 countries in Africa, Asia, Latin America and the Middle East showed that the incidence was $0.5 \%(170 / 37366)$ in women who had had CS at least once, ranging from $0.2 \%$ in high-Human Development Index (HDI) countries to $1.0 \%$ in low-HDI countries. ${ }^{7}$ In developing countries, obstructed labour, injudicious obstetric interventions or manipulations, lack of antenatal care, poor access to emergency obstetric care and low socioeconomic status were common causes for uterine rupture with adverse outcomes. $^{8}$

Previous CS is the most important risk factor for uterine rupture. Since China has experienced a high CS rate during the last two decades and the implementation of two-child and three-child policy in recent years, it is suspected that uterine rupture might have increased. ${ }^{9}$ However, uterine rupture is uncommon, and the national estimate of the incidence of uterine rupture and in-depth epidemiological analysis are lacking in China. Thus, we used data from the China Labor and Delivery Survey to estimate the incidence of uterine rupture in a large contemporary population, to describe factors associated with uterine rupture in women with a scarred uterus, and to develop a predictive model for uterine rupture for better clinical management and monitoring.

\section{METHODS}

\section{Study design and sample}

The China Labor and Delivery Survey was a multicentre cross-sectional study across the country between 1 March 2015 and 31 December 2016. Participating hospitals were recruited through obstetric conferences and networks. Only hospitals with 1000 or more deliveries per year were eligible. Data collection was randomly selected for 6 weeks within a 12-month period for hospitals with at least 6000 annual deliveries or 10 weeks for hospitals with fewer than 6000 annual deliveries. Within the selected weeks, all births at 24 completed weeks of gestation or more or a birth weight of $\geq 500 \mathrm{~g}$ were included. Medical records were retrieved and deidentified information on maternal sociodemographic characteristics, medical histories, pregnancy and labour complications and perinatal outcomes was extracted by trained staff. Data extraction protocols and operating manuals were developed to guide data extraction. The completed data extraction forms were reviewed by the data manager for completeness before they were entered into the database. The data management system was programmed with built-in logic checks to verify the consistency of related variables and acceptable values. Detailed description on sampling and data management have been published elsewhere. $^{10}$

The survey included 96 hospitals located in 24 (of 34) provinces, autonomous regions and municipalities in China. As our cross-sectional study collected deidentified data from medical records, a patient consent was waived by the ethical committee.

\section{Definitions}

In our study, uterine rupture included both complete and incomplete rupture. A complete uterine rupture was defined as tears that penetrate all layers of the uterine wall, including serosa and amniotic membrane, while an incomplete uterine rupture was defined as a tear in the muscle layer with a still complete serous membrane or amniotic membrane. ${ }^{11}$ The diagnosis and the type of uterine rupture were extracted from medical records. Due to the small number of rupture cases, we combined them together as the total incidence in the analysis.

The hospital level is officially determined by the local government (secondary and tertiary hospital) according to the standard criteria. ${ }^{12}$ We grouped maternal age into younger than 25, 25.0-29.9, 30.0-34.9 and 35 years and older. Maternal prepregnancy body mass index (BMI) was categorised into underweight $\left(<18.5 \mathrm{~kg} / \mathrm{m}^{2}\right)$, normal weight $\left(18.5-23.9 \mathrm{~kg} / \mathrm{m}^{2}\right)$, overweight $\left(24-27.9 \mathrm{~kg} / \mathrm{m}^{2}\right)$ and obese $\left(\geq 28 \mathrm{~kg} / \mathrm{m}^{2}\right) .{ }^{13}$ We divided the education level of pregnant women into low (illiterate, primary school and junior school), middle (high school, technical school and junior college) and high (college or higher degree). Maternal characteristics and prenatal conditions included parity, history of miscarriage and CS, assisted reproductive technology, prepregnancy diabetes, anaemia, hypertensive disorders in pregnancy (including chronic hypertension, gestational hypertension and preeclampsia), gestational diabetes and labour induction. Also included were fetal conditions, such as fetal presentation, multiple pregnancy and stillbirth.

\section{Statistical analysis}

To improve the representativeness of the study population, we used the number of births in each province in the 2016 China Statistical Yearbook compiled by the National Bureau of Statistics of China to calculate the weight of each baby in the Survey (http://www.stats.gov.cn/tjsj/ ndsj/2016/indexch.htm). We treated the hospital level as a poststratification factor, and stratified the number of deliveries per year in each city by hospital level. We assigned a weight to each birth based on the inverse probability weighting, which took into account the number of deliveries in provinces at the same hospital level and the number of records examined in hospitals at the same hospital level. ${ }^{14}$ We used the bootstrap method to calculate the $95 \%$ CI for the incidence of uterine rupture. ${ }^{15}$

Multivariable logistic regression was used to analyse the relationship between maternal medical conditions and uterine rupture. Based on the OR, a risk score for each risk factor was calculated using the corresponding OR divided by the smallest risk ratio among all significant variables $(\mathrm{p}<0.05)$. An individual's summary risk score is the sum of the risk scores of all items. This method has been used in previous researches. ${ }^{16}$ ROC and the area under the curve were used to assess the predictive value of different models. Calibration was assessed using the Hosmer-Lemeshow goodness-of-fit test and satisfied when $\mathrm{p}$ value was $>0.05$. The ROC curve shows how the 
true-positive rate varies with the false-positive rate. We used R software (V.3.6.3) to perform all the analyses.

\section{Patient and public involvement}

Patients and the public were not involved in the design, conduct or reporting in our study.

\section{RESULT}

Our study initially included 77789 birth records in 96 hospitals distributed in 24 provinces. We excluded 2567 births of less than 24 gestational weeks or unknown gestational age, and 1042 births with unknown status of uterine rupture, leaving 74180 births for the final analysis. Multiparas accounted for $43.9 \%$ of all pregnancies. Overall, the weighted incidence of uterine rupture, including complete and incomplete uterine rupture, was $0.18 \%$ (95\% CI $0.05 \%$ to $0.23 \%$ ) during $2015-2016$. The incidence of complete uterine rupture was $0.01 \%(95 \%$ CI $0.00 \%$ to $0.02 \%$ ). Scarred uterus accounted for $16.7 \%$ of the population, with $0.9 \%$ in nulliparas and $36.8 \%$ in multiparas. The weighted uterine rupture rates in women with a scarred and intact uterus were $0.79 \%(95 \%$ CI $0.63 \%$ to $0.91 \%$ ) and $0.05 \%$ (95\% CI $0.02 \%$ to $0.13 \%$ ), respectively.

Table 1 presents unadjusted and adjusted ORs with 95\% CIs for uterine rupture in women with a scarred uterus. CS more than once had the highest risk for uterine rupture (adjusted OR 3.2, 95\% CI 3.0 to 3.4), followed by placenta previa (adjusted OR 2.6, 95\% CI 2.4 to 2.8 ), multiple induced abortions $(\geq 2)$ (adjusted OR 2.3, 95\% CI 2.1 to 2.3) and gestational diabetes (adjusted OR 2.1, $95 \%$ CI 1.9 to 2.3 ). In addition to the above four relatively influential variables $(\mathrm{OR}>2)$, other risk factors were all related to the increased risk of uterine rupture except for labour induction. The association between maternal characteristics and complete uterine rupture is presented in online supplemental table 1).

We further developed three prediction models for uterine rupture and assessed the predictive values by comparing the area under the ROC curve (model 1: all variables; model 2: eight variables with $\mathrm{OR}>1.5$; model 3: four variables with $\mathrm{OR}>2$ ). The results show that the model incorporating eight significant variables has the highest predictive value according to the area under the ROC curve and the moderate complexity of the model (model 1: $0.81,95 \%$ CI 0.77 to 0.84 ; model 2: $0.81,95 \%$ CI 0.78 to 0.85 ; model $3: 0.70,95 \%$ CI 0.65 to 0.76 ) (figure 1). Model 2 produced a total score ranging from 0 to 24.5 points. The cut-off value of the prediction model was 6.5 , determined by the highest Youden index. The corresponding sensitivity and specificity were $77.2 \%$ and $69.8 \%$, respectively. Based on the cut-off value, pregnant women were divided into two groups: low risks $(0-6.5$ points: the incidence rate of uterine rupture was $0.21 \%$ ) and high risks (6.5-24.5 points: the incidence rate of uterine rupture was 2.83\%) (table 2). The HosmerLemeshow $\chi^{2}$ test is presented in figure 2 .

\section{DISCUSSION}

\section{Main findings}

In our large study population, the overall uterine rupture rate was $0.18 \%$ (95\% CI $0.05 \%$ to $0.23 \%$ ) in 2015 and 2016. The rate was $0.79 \%$ (95\% CI $0.63 \%$ to $0.91 \%$ ) for women with a scared uterus but $0.05 \%$ (95\% CI $0.02 \%$ to $0.13 \%$ ) for those with an intact uterus. The multivariable prediction model based on age, prepregnancy BMI, hospital level, number of previous CS, number of previous induced abortion, anaemia, gestational diabetes and placenta previa had a moderate performance in predicting uterine rupture in women with a scarred uterus.

\section{Interpretation}

The incidence of uterine rupture in our study population was $0.18 \%$, which differs from other countries. Few studies reported the epidemiology of uterine rupture. A systematic review conducted by the WHO in 2005 showed that according to five studies from high-income countries, the median incidence rate was $0.50 \%$ (ranging from $0.16 \%$ to $0.70 \%$ ) from 1995 to $1998 .{ }^{17}$ A New Zealand study in a referral hospital found that the incidence of complete uterine rupture was $0.84 \%$ among all the deliveries $(95 \%$ CI $0.59 \%$ to $1.18 \%) .{ }^{18}$ In the USA, the incidence of uterine rupture was $0.24 \%$ among all the deliveries $(95 \%$ CI $0.23 \%$ to $0.25 \%$ ) based on the vital statistics data in 2011-2012. ${ }^{5}$ In general, the incidence of uterine rupture was higher in low-income and middle-income countries and lower in high-income countries. However, as China has a very high repeat CS rate and a low TOLAC rate, ${ }^{19}$ the uterine rupture rate in our study population is even lower than that in some developed countries. ${ }^{720}$

Our study shows that advanced maternal age is a risk factor for uterine rupture among pregnant women with a scarred uterus, which is consistent with the results of other studies. Research in the Netherlands, Sweden and Norway have shown that age over 35 or 40 years greatly increased the risk of uterine rupture. The myometrium may undergo age-related morphological changes, accompanied by decreased tissue durability, which can be seen in other muscles that change with age. ${ }^{21}$ Studies from uterine biopsies suggested that with age, the cholesterol content of muscular cells increased, ${ }^{22}$ and the connective tissue between the muscular muscle bundles increased..$^{21}{ }^{22}$ These age-related muscle changes or other undefined processes may gradually increase the risk of uterine rupture.

We also found that placenta previa was an independent risk factor for uterine rupture in pregnant women. This may be attributable to the fact that the placenta implantation changes the thickness of the endometrium and the elasticity of the myometrium, which is more prone to rupture. ${ }^{23}$ In our study, previous induced abortion was associated with an increased risk of uterine rupture. Evidence suggested that thinning the uterine wall through curettage may greatly increase the risk of rupture. ${ }^{24} 25$ However, the main procedure of early induced abortion 
Table 1 Maternal characteristics and their associations with uterine rupture in China, 2015-2016

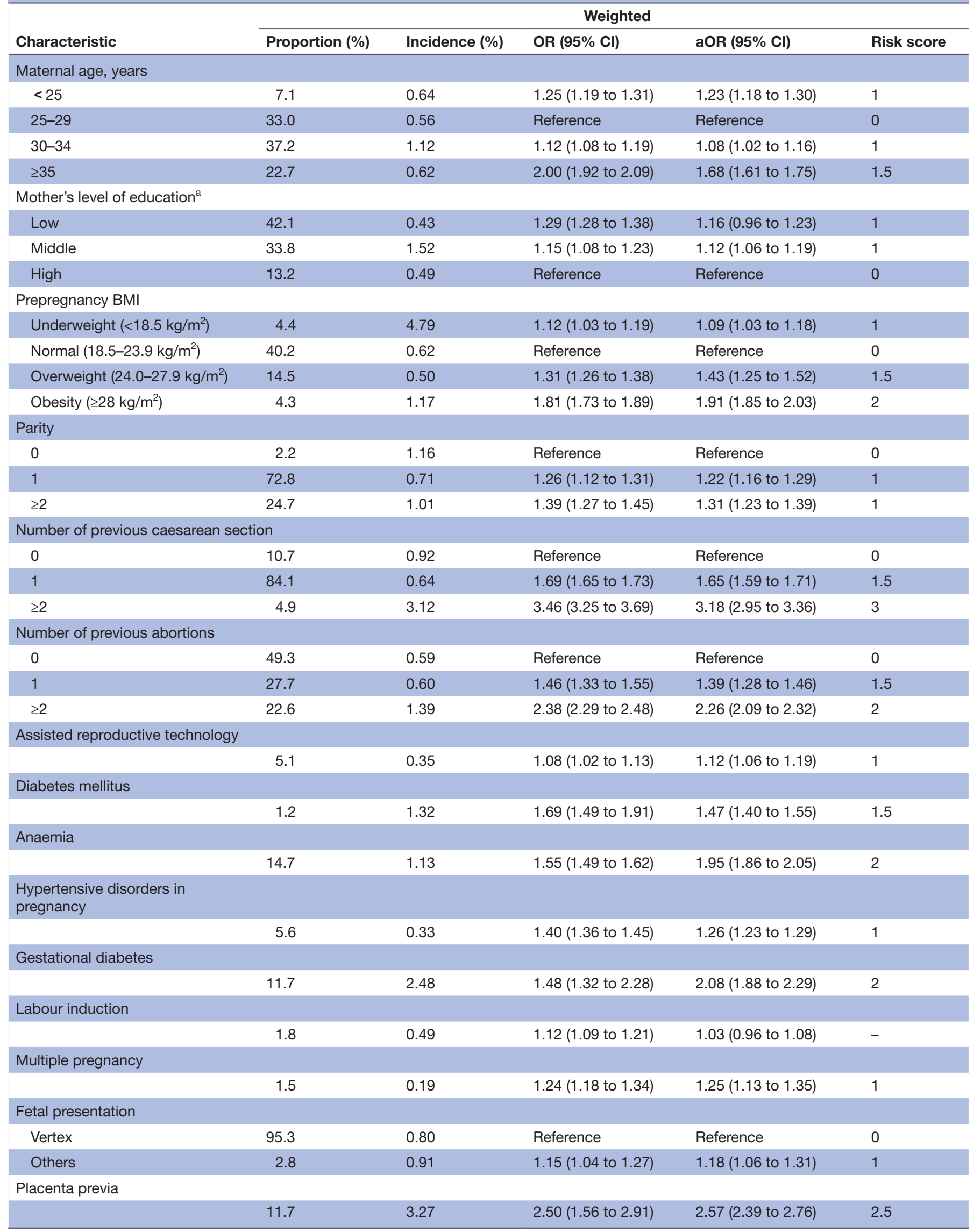


Table 1 Continued

\begin{tabular}{|c|c|c|c|c|c|}
\hline \multirow[b]{2}{*}{ Characteristic } & \multicolumn{5}{|c|}{ Weighted } \\
\hline & Proportion (\%) & Incidence (\%) & OR $(95 \% \mathrm{Cl})$ & aOR (95\% Cl) & Risk score \\
\hline \multicolumn{6}{|c|}{ Antepartum stillbirth } \\
\hline \multicolumn{6}{|l|}{ Hospital level } \\
\hline Secondary & 55.3 & 0.24 & Reference & Reference & 0 \\
\hline
\end{tabular}

aOR, logistic regression adjusting for all other variables in the table; BMI, body mass index calculated as weight in kilograms divided by height in metres squared.

has been vacuum aspiration in China. Thus, accidental perforation of the uterine wall during the procedure causing a uterine scar may be a more plausible explanation. Unfortunately, we did not have detailed information on previous induced abortions.

In the past 10 years, elective repeat CS has become the primary reason for the high rate of CS in many countries and regions. ${ }^{26}$ With the implement of the "two-child and three-child' policy in China, repeat CS has increased rapidly, mainly due to the fear of uterine rupture and lack of confidence in TOLAC. ${ }^{27}{ }^{28}$ Many hospitals also lack adequate emergency rescue capability. However, repeat CS is also not risk free. Repeat CS increases the risks of postpartum haemorrhage, placental implantation and hysterectomy in future pregnancies. Previous studies have showed that the success rate of vaginal birth after caesarean (VBAC) has reached $60 \%-80 \% .{ }^{2930}$ Studies also demonstrated that compared with repeat CS, successful VBAC had a lower incidence of postpartum haemorrhage, neonatal respiratory disease, shorter hospital stay and faster postpartum recovery. ${ }^{31}{ }^{32}$ However, the incidence of complications in VBAC failures is five times that of successful VBACs, among which uterine rupture is one of the most common complications. ${ }^{33} 34$ Previous studies have reported that the risk of uterine rupture in VBAC patients ranged from $0.2 \%$ to $0.5 \% .{ }^{35}{ }^{36}$ It is indeed a delicate balance between taking a small but potentially catastrophic risk and avoiding potentially serious complications in future pregnancies.

Previous investigations on this topic focused on aetiological models and identified factors independently related to uterine rupture. Such studies were valuable in identifying factors related to increased or decreased risks of rupture (eg, the number of previous CS) ${ }^{37}{ }^{38}$ However, this epidemiological association does not always help accurately predict the prognosis of women. As clinical practice develops towards personalised medicine, there is an increasing demand for reliable predictive tools to help doctors make appropriate treatment decisions by integrating several influencing factors. Therefore, it is of great clinical significance to establish the risk prediction model of uterine rupture for pregnant women with a scarred uterus. In this study, we identified eight significant risk factors, and a predictive risk score of uterine rupture was obtained by adding each score. The summary risk score was relatively simple. It may help clinicians to make a preliminary judgement on the risk of uterine rupture. High-risk patients may need frequent monitoring, preventive strategies and even priority treatment in order to achieve a good pregnancy outcome.

Few predicting models for uterine rupture were published so far. In 2006, investigators in the USA developed a clinical prediction model for the occurrence of uterine rupture by using both antepartum and early
(A)

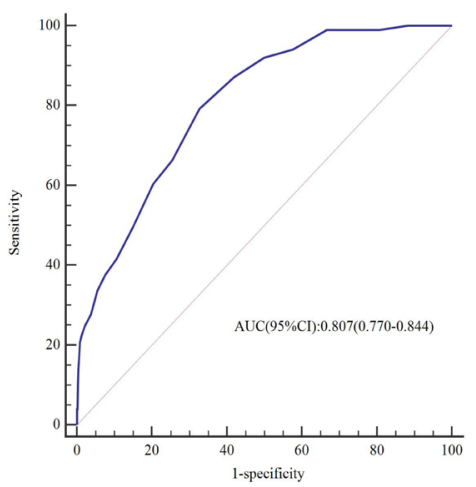

(B)

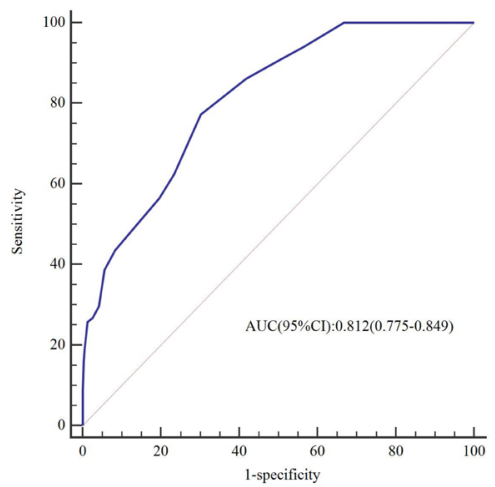

(C)

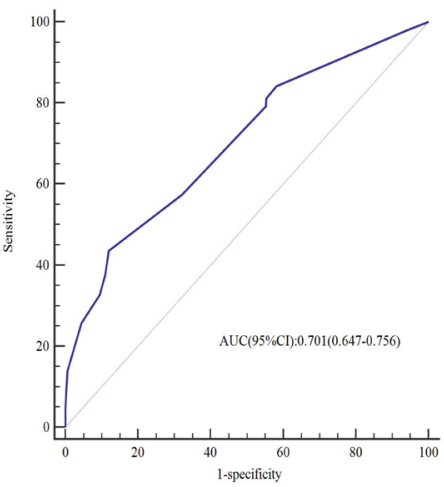

Figure 1 ROC curve for three different prediction models (figure part A included all variables in table 1; figure part B included eight variables with $O R>1.5$; figure part $C$ included four variables with or $>2$ ). 
Table 2 Effects of the predictive model (using the optimal cut-off values according to the ROC curve) on predictive accuracy for uterine rupture

\begin{tabular}{|c|c|c|c|c|c|c|c|c|c|}
\hline Model & AUC & $\begin{array}{l}\text { Cut-off } \\
\text { score }\end{array}$ & Groups & OR (95\% Cl) & Sensitivity (\%) & Specificity (\%) & $\begin{array}{l}\text { Youden } \\
\text { index }\end{array}$ & FPR (\%) & FNR (\%) \\
\hline Model $1^{*}$ & 0.807 & 8.5 & Low risk & 1.00 & 79.2 & 67.3 & 0.465 & 32.7 & 20.8 \\
\hline \multirow[t]{2}{*}{ Model $2^{*}$} & 0.812 & 6.5 & Low risk & 1.00 & 77.2 & 69.8 & 0.470 & 30.2 & 22.8 \\
\hline & & & High risk & 1.77 (1.62 to 1.93$)$ & & & & & \\
\hline
\end{tabular}

*Model 1: all meaningful variables (all variables except labour induction); Model 2: eight meaningful variables (OR >1.5) (including maternal age, prepregnancy BMI, number of previous caesarean section, number of previous abortions, anaemia, gestational diabetes, placenta previa and hospital level); model 3: four meaningful variables $(\mathrm{OR}>2$ ) (including number of previous caesarean section, number of previous abortions, gestational diabetes and placenta previa).

FNR, false negative rate; FPR, false positive rate.

intrapartum factors. The prenatal model included four factors of maternal age, gestational age at delivery, ethnicity and prior vaginal delivery, while the perinatal model includes six factors of maternal age, gestational age at delivery, ethnicity, prior vaginal delivery, cervical dilation and labour induction. The results showed that the area under the ROC curve of the two models were 0.67 and 0.7 , respectively. ${ }^{39}$ Comparing to predictive performance in our study, our model appeared to have improved moderately (including the AUC (0.812), sensitivity $(77.2 \%)$ and specificity $(69.8 \%))$. Clinicians can calculate the variable scores and sum them according to the values of eight meaningful variables for each woman, and then estimate the possible incidence of uterine rupture based on the total score.

Our research has several strengths. First, the China Labor and Delivery Survey included 96 hospitals covering most of China's geographic regions. In the past 10 years, births in secondary and tertiary hospitals accounted for more than $90 \%$ of births in China. ${ }^{40}$ Therefore, our results also represent deliveries in large secondary and tertiary hospitals in China. Second, our study is one of the first studies in China to consider births at 24 weeks of gestation. We used the same data collection form in all hospitals, which made the comparison more consistent and reliable. Third, we have established a predictive model for the risk of uterine rupture in pregnant women with a scarred uterus in a large Chinese population for the first time. As China still has a high CS rate, this information is useful for clinicians to develop monitoring, follow-up and intervention strategies for pregnant women who are at a high risk of uterine rupture.

\section{Limitations}

Despite the large sample size, our study still has some limitations. First, our participants were not a random sample of all births in China. The hospitals included were self-selected centres with $>1000$ annual deliveries. Some provinces had no participating hospitals; we had more tertiary hospitals than secondary hospitals, and there were no primary hospitals. Such research samples may lead to certain degree of bias in the estimation of the incidence of uterine rupture. However, few primary hospitals deliver babies in China, and the delivery volume in these hospitals are usually small. There is neither a uterine rupture registration system nor a large-scale epidemiological survey in rural China.

However, because most high-risk pregnant women are transferred to tertiary hospitals for better perinatal care, the incidence of uterine rupture in tertiary hospitals with
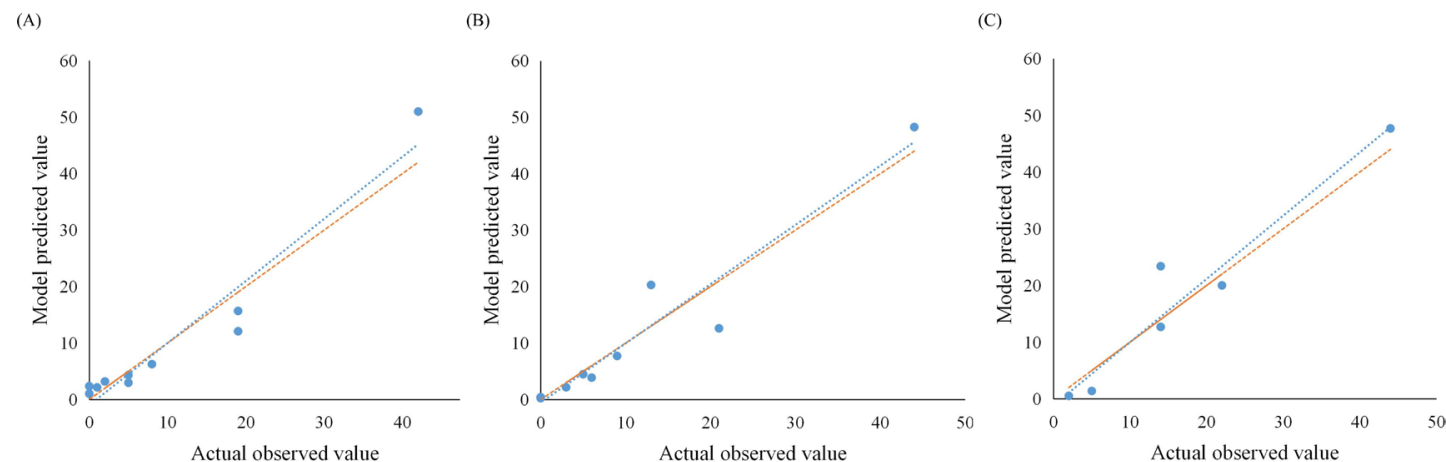

Figure 2 Calibration curve of the prediction model. The red dotted line refers to the standard curve, while the blue dotted line is the straight line fitted between the actual observed value and the predicted value of the model figure part $A$ included all variables in table 1; figure part $B$ included eight variables with or $>1.5$; figure part $C$ included four variables with or $>2$ ). 
advanced facilities is significantly higher than that in secondary hospitals. Therefore, the referral system may have led to an overestimation of the incidence of uterine rupture. In order to improve the representativeness of our study population, we stratified the hospital level as the main sampling unit when calculating the weighted value to reduce these deviations.

Second, because not all hospitals have a unified definition of pregnancy complications and diseases. Therefore, some misclassifications may have occurred. However, we tried to minimise this impact by using a standardised data collection process across the facilities and training data collectors. Third, our study was based on a crosssectional survey conducted between 1 March 2015 and 31 December 2016. Thus, we were unable to explore the trend of uterine rupture with time. Finally, our predication model needs independent validations in different population before any clinical application.

\section{CONCLUSION}

The overall incidence of uterine rupture was $0.18 \%(95 \%$ CI $0.05 \%$ to $0.23 \%$ ) in our population in $2015-2016$. A predictive model based on eight easily available variables was established to predict the risk of uterine rupture in women with a scarred uterus. It showed good calibration and identification accuracies. Further external validations in different populations are warranted before any clinical applications.

\section{Author affiliations}

${ }^{1}$ Ministry of Education-Shanghai Key Laboratory of Children's Environmental Health, Xinhua Hospital Affiliated to Shanghai Jiaotong University School of Medicine,

Shanghai, China

${ }^{2}$ School of Public Health, Shanghai Jiao Tong University School of Medicine, Shanghai, China

${ }^{3}$ The International Peace Maternal and Child Health Hospital, Shanghai Jiao Tong University School of Medicine, Shanghai, China

${ }^{4}$ Shanghai Key Laboratory of Embryo Original Diseases, Shanghai, China

${ }^{5}$ Department of Obstetrics, Shanghai First Maternity and Infant Hospital, Tongji University School of Medicine, Shanghai, China

${ }^{6} \mathrm{KK}$ Women's and Children's Hospital, Singapore

${ }^{7}$ Hainan Women and Children's Medical Center, Haikou, Hainan, China

Contributors JZhang accepts full responsibility for the work and the conduct of the study, had access to the data, and controlled the decision to publish. Study concept and design: JZhang and QC. Data collection: WZ, JZhu and JY. Drafting of the manuscript: WZ, JZhu and JZhang. Statistical analysis: WZ, JZhu, XH, QC and JZhang. All authors revised the manuscript and approved the final version.

Funding The project was supported in part by Shanghai Municipal Health Commission (GWV-26.2) and Hainan Provincial Medical Center Program.

Disclaimer The funders did not play any role in the study design, data collection and analysis, decision to publish or preparation of the manuscript.

Competing interests None declared.

Patient consent for publication Not applicable.

Ethics approval The study was approved by the Xinhua Hospital Affiliated to Shanghai Jiao Tong University School of Medicine Ethics Review Committee (XHEC-C-2015-006), the Research Project Review Panel (RP2) of the UNDP/ UNFPA/UNICEF/WHO/World Bank Special Programme of Research, Development and Research Training in Human Reproduction, at the Department of Sexual and Reproductive Health and Research at the WHO, by the WHO Research Ethics Review Committee (HRP Study A65899) and participating hospitals.
Provenance and peer review Not commissioned; externally peer reviewed.

Data availability statement All data relevant to the study are included in the article or uploaded as supplementary information.

Supplemental material This content has been supplied by the author(s). It has not been vetted by BMJ Publishing Group Limited (BMJ) and may not have been peer-reviewed. Any opinions or recommendations discussed are solely those of the author(s) and are not endorsed by BMJ. BMJ disclaims all liability and responsibility arising from any reliance placed on the content. Where the content includes any translated material, BMJ does not warrant the accuracy and reliability of the translations (including but not limited to local regulations, clinical guidelines, terminology, drug names and drug dosages), and is not responsible for any error and/or omissions arising from translation and adaptation or otherwise.

Open access This is an open access article distributed in accordance with the Creative Commons Attribution Non Commercial (CC BY-NC 4.0) license, which permits others to distribute, remix, adapt, build upon this work non-commercially, and license their derivative works on different terms, provided the original work is properly cited, appropriate credit is given, any changes made indicated, and the use is non-commercial. See: http://creativecommons.org/licenses/by-nc/4.0/.

ORCID iD

Jun Zhang http://orcid.org/0000-0003-1706-1611

\section{REFERENCES}

1 Schaap T, Bloemenkamp K, Deneux-Tharaux C, et al. Defining definitions: a Delphi study to develop a core outcome set for conditions of severe maternal morbidity. BJOG 2019;126:394-401.

2 Ronel D, Wiznitzer A, Sergienko R, et al. Trends, risk factors and pregnancy outcome in women with uterine rupture. Arch Gynecol Obstet 2012;285:317-21.

3 Keag OE, Norman JE, Stock SJ. Long-term risks and benefits associated with cesarean delivery for mother, baby, and subsequent pregnancies: systematic review and meta-analysis. PLOS Med 2018;15:e1002494.

4 Al-Zirqi I, Stray-Pedersen B, Forsén L, et al. Uterine rupture: trends over 40 years. BJOG 2016;123:780-7.

5 Vilchez G, Nazeer S, Kumar K, et al. Contemporary epidemiology and novel predictors of uterine rupture: a nationwide population-based study. Arch Gynecol Obstet 2017;296:869-75.

6 Al-Zirqi I, Vangen S. Prelabour uterine rupture: characteristics and outcomes. BJOG 2020;127:1637-44.

7 Motomura K, Ganchimeg T, Nagata C, et al. Incidence and outcomes of uterine rupture among women with prior caesarean section: who multicountry survey on maternal and newborn health. Sci Rep 2017;7:44093.

8 Guise J-M, McDonagh MS, Osterweil P, et al. Systematic review of the incidence and consequences of uterine rupture in women with previous caesarean section. BMJ 2004;329:19-25.

9 Smith JG, Mertz HL, Merrill DC. Identifying risk factors for uterine rupture. Clin Perinatol 2008;35:85-99.

10 Zhu J, Zhang J, Xia H, et al. Stillbirths in China: a nationwide survey. BJOG 2021;128:67-76.

11 Nahun GG, Pham KQ, Chelmow D. Uterine rupture in pregnancy. In: Medscape reference, 2012.

12 Ministry of Health, China. The measures for hospital evaluation. Ministry of Health, China (in Chinese), 2011.

$13 \mathrm{He} \mathrm{W}$, Li Q, Yang M, et al. Lower BMI cutoffs to define overweight and obesity in China. Obesity 2015;23:684-91.

14 Vasconcellos MTLde, Silva PLdoN, Pereira APE, et al. Sampling design for the birth in Brazil: national survey into labor and birth. Cad Saude Publica 2014;30 Suppl 1:S1-10.

15 Kirby KN, Gerlanc D. BootES: an R package for bootstrap confidence intervals on effect sizes. Behav Res Methods 2013;45:905-27.

16 Grobman WA, Lai Y, Landon MB, et al. Prediction of uterine rupture associated with attempted vaginal birth after cesarean delivery. Am J Obstet Gynecol 2008;199:30.e1-30.e5.

17 Hofmeyr GJ, Say L, Gülmezoglu AM. Who systematic review of maternal mortality and morbidity: the prevalence of uterine rupture. BJOG 2005;112:1221-8.

18 Chang $\mathrm{Y}-\mathrm{H}$. Uterine rupture over 11 years: a retrospective descriptive study. Aust N Z J Obstet Gynaecol 2020;60:709-13.

19 Zhang Y, Betran AP, Li X, et al. What is an appropriate caesarean delivery rate for China: a multicentre survey. BJOG: Int J Obstet Gy $2021 ; 11$. 
20 Berhe Y, Wall LL. Uterine rupture in resource-poor countries. Obstet Gynecol Surv 2014;69:695-707.

21 Arrowsmith S, Robinson H, Noble K, et al. What do we know about what happens to myometrial function as women age? J Muscle Res Cell Motil 2012;33:209-17.

22 Smith GCS, Cordeaux Y, White IR, et al. The effect of delaying childbirth on primary cesarean section rates. PLoS Med 2008;5:e144

23 Uccella S, Cromi A, Bogani G, et al. Spontaneous prelabor uterine rupture in a primigravida: a case report and review of the literature. Am J Obstet Gynecol 2011;205:e6-8.

24 Gibbins KJ, Weber T, Holmgren CM, et al. Maternal and fetal morbidity associated with uterine rupture of the unscarred uterus. Am J Obstet Gynecol 2015;213:382.e1-382.e6.

25 Nkwabong E, Kouam L, Takang W. Spontaneous uterine rupture during pregnancy: case report and review of literature. Afr J Reprod Health 2007;11:107-12.

26 Vusirikala K, Kak H, Greer O, et al. Intrapartum management of trial of labour after caesarean delivery: evidence and experience. BJOG 2014;121:911.

27 Practice Bulletin No. 115: vaginal birth after previous cesarean delivery. Obstet Gynecol 2010;116:450-63.

28 Hauk L, American Academy of Family Physicians. Planning for labor and vaginal birth after cesarean delivery: guidelines from the AAFP. Am Fam Physician 2015;91:197-8.

29 Holmgren C, Scott JR, Porter TF, et al. Uterine rupture with attempted vaginal birth after cesarean delivery: decision-to-delivery time and neonatal outcome. Obstet Gynecol 2012;119:725-31.

30 Wu Y, Kataria Y, Wang Z, et al. Factors associated with successful vaginal birth after a cesarean section: a systematic review and metaanalysis. BMC Pregnancy Childbirth 2019;19:360.

31 İzbudak G, Tozkır E, Cogendez E, et al. Comparison of maternalneonatal results of vaginal birth after cesarean and elective repeat cesarean delivery. Ginekol Pol 2021;92:306-311.
32 Pont S, Austin K, Ibiebele I, et al. Blood transfusion following intended vaginal birth after cesarean vs elective repeat cesarean section in women with a prior primary cesarean: a populationbased record linkage study. Acta Obstet Gynecol Scand 2019;98:382-9.

33 Haumonte J-B, Raylet M, Christophe M, et al. French validation and adaptation of the Grobman nomogram for prediction of vaginal birth after cesarean delivery. J Gynecol Obstet Hum Reprod 2018;47:127-31.

34 Patel MD, Maitra N, Patel PK, et al. Predicting successful trial of labor after cesarean delivery: evaluation of two scoring systems. $J$ Obstet Gynaecol India 2018;68:276-82.

35 Atia $\mathrm{H}$, Ellaithy $\mathrm{M}$, Altraigey $\mathrm{A}$, et al. Mechanical induction of labor and ecbolic-less vaginal birth after cesarean section: a cohort study. Taiwan J Obstet Gynecol 2018;57:421-6.

36 Ashwal E, Hiersch L, Melamed N, et al. Pregnancy outcome after induction of labor in women with previous cesarean section. $J$ Matern Fetal Neonatal Med 2015;28:386-91.

37 Salman L, Hiersch L, Shmueli A, et al. Complicated primary cesarean delivery increases the risk for uterine rupture at subsequent trial of labor after cesarean. Arch Gynecol Obstet 2018;298:273-7.

38 Macones GA, Cahill A, Pare E, et al. Obstetric outcomes in women with two prior cesarean deliveries: is vaginal birth after cesarean delivery a viable option? Am J Obstet Gynecol 2005;192:1223-8.

39 Macones GA, Cahill AG, Stamilio DM, et al. Can uterine rupture in patients attempting vaginal birth after cesarean delivery be predicted? Am J Obstet Gynecol 2006;195:1148-52.

40 Zhu J, Liang J, Mu Y, et al. Sociodemographic and obstetric characteristics of stillbirths in China: a census of nearly 4 million health facility births between 2012 and 2014. Lancet Glob Health 2016;4:e109-18. 